\title{
Multicultural Education: Some Reflections on the Spanish Case
}

\author{
F. Javier Garcia-Castaño and Rafael A. Pulido Moyano
}

In this paper we succinctly describe some aspects related to multicultural education in Spain. First we must recognise that there exists a somewhat extensive and significant work on Gypsies (the most important ethnic group in Spain) that we do not include in this paper, because it would require a separate article. It is much more interesting, we hope, to present the state of art of discourses and practices related to multicultural education in our country. In fact, we argue Spanish authorities have never considered the education of Gypsy children as a matter of multicultural education. The very phrases 'multicultural education' and 'intercultural education' have only recently been introduced in Spain.

In the first section of this paper we describe the reasons put forth by some authors to support intercultural education. Their rationale for more multicultural education is compared to our own reasons. Sections number two to five briefly review some congresses on multicultural education held in our country (II), current research (III), legislation (IV), and programs in action (V). The common feature of these sections is the emphasis on showing how scarce and recent the whole topic of multiculturalism is in Spain. However, many Spanish investigators and educators are beginning to work in this field, and government involvement is rapidly growing.

\section{Discourses on multicultural education in Spain}

References to multicultural education or intercultural education are gradually becoming more frequent in Spain. There have been many scientific meetings, increased budgets for research in the field, and the first publications by Spanish authors. Some say that multicultural education 'is in fashion,' perhaps because fashion is present in the development of science. If we ask for the reasons of increasing interest in the issue of multiculturalism we will discover that, in the Spanish case, a geopolitical component rather than a scientific one lies at the basis. Let us succinctly review three explanations given to explain the rise of multicultural education, as put forth by several authors, and assess whether they apply in our country.

- Multicultural education arises once we understand and recognise the diversity of people in a country. If this is what happened in Spain, we must ask ourselves why this understanding and recognition appear at this moment in time. It is 
clear that diversity has always been among us, that we have always been diverse, as ten or fifteen years of self-governed regions show.

- Multicultural education comes into being when ethnic groups are present other than those whose schooling rights have been recognised. In Spain, Gypsies have been the only group in this situation. Yet, nobody has ever framed their educational problems as a multicultural education issue, but only as a compensatory and/or assimilation issue.

- Related to the latter, some people think that multicultural education appears due to the presence of foreign immigrants. In Spain, we can trace this immigrant presence back ten or more years, when Spanish people were themselves immigrants (as is still the case today). Those first foreign immigrants came to Spain from Western Europe or First World countries (see table 1). Their educational needs were not formulated within a multicultural education context. Sometimes, these migrants established their own schools in Spain.

\section{Table 1: RESIDENT FOREIGNERS IN SPAIN. EVOLUTION 1955-1991}

$\begin{array}{lll}\text { YEAR } & \text { 1st WORLD } & \text { 3rd WORLD } \\ 1965 & 50,181(75.98 \%) & 14,160(21.44 \%) \\ 1970 & 129,409(69.69 \%) & 43,983(29.63 \%) \\ 1980 & 130,598(71.20 \%) & 50,964(27.78 \%) \\ 1985 & 173,413(71.66 \%) & 67,564(27.92 \%) \\ 1991 & 296,844(54.91 \%) & 240,622(44.51 \%)\end{array}$

Cited by Colectivo IOE (Source: Comisaria General de Documentación, Dirección General de Migraciones and Instituto Nacional de Estadística).

From our point of view, current references to multicultural education in Spain tend to deal with very recent issues. We think that there are three direct reasons to consider the issue of multicultural education in our country, although many of those who employ the terms 'multicultural education' or 'intercultural education' do not recognise such reasons:

- Multicultural education only became a topic of discussion when the number of migrants in our country and schools became significant. We must remember that it is the presence of Third World migrants that has promoted a discourse on multicultural education. The specific educational treatment of this population became an arena for public discussion only when their number reached the level of First World migrants. In a sense, this discourse deals with a type 
of multicultural education aimed to answer questions such as: What can we do with cultures that are so diverse and strange to Western societies? In short, it is a type of multicultural education designed to protect and to compensate.

- For many educators, multicultural education is considered necessary given our nation's new political situation, caused by our inclusion in the European Community, an inclusion that leads to educational adaptions. It is a conception of multicultural education based on the future projections regarding the European labour market. It is multicultural education in order to remain competitive.

- One reason relates specifically to the Spanish universities. With the program reforms taking place in the Educational Sciences, some departments (mostly Theory and Philosophy of Education) have a more limited working area, and they are trying to 'discover' new fields. Multicultural education could be one of these academic lifejackets.

In brief, these represent three reasons, explanations, or justifications for Spanish multiculturalism. In our view, multicultural education arises at the same moment that the concept 'culture' is introduced into classrooms, not as an analytical variable but as a variable that represents already existing diversity. There are different minority groups in the schools (because of different skin colour, mother language, religious values and behaviours and socio-economic differences) and we therefore need 'special' education to meet the demands of these differences. At the present moment, schools discriminate against people in a new way: discrimination based on cultural differences, a new discrimination defined by sex, class and race discrimination. We will discuss what kinds of discourses recently been constructed in Spain in relation to this topic. More specifically, we will summarise some recent arguments embraced by Spanish educators.

\section{Meetings}

\subsection{Ceuta Congress}

We shall start by discussing this congress because it was the first meeting organised by educators which focused on these topics and strove for an international dimension, as reflected by the participation of foreign scholars. It is difficult to comment on earlier meetings because there is limited access to papers.

In Ceuta, educators agreed that 'intercultural education' was the most accurate term to describe their views. Generally speaking, discourses at Ceuta were often characterised by naive argumentation and suggestions. Furthermore, there was (there is) an almost complete lack of knowledge about key topics. For example, one author dealt with Gypsies as an immigrant minority population, grouping them with the Portuguese and the Magrebians (Pérez 1992, 58). Another author, adopting a very dangerous ethnocentric stance, wrote: 
During the XI International Congress of Comparative Education (Wurzburgo, 1983), an African commented that 'all cultures are equal', and everybody showed a great discrepancy with this opinion [ ...] [We think that] all cultures have an intrinsic value, because all of them are equally useful to adapt their members to their respective societies, but this is the reason why cultures have a relative value [ ...] [Latin Americans] seem to forget that pre-Columbus people lived in a prehistorical situation, given that they lived in illiteracy and had not yet discovered the wheel, which constitutes an uninteresting way of life. Scientific and technological cultures have advantages that other cultures lack. (Quintana 1992, $75)$.

For some participants, intercultural education problems were temporary. Their solution was simply a matter of time... if we are ready to wait:

The sociocultural integration of immigrants used to follow this process: First generation (worker parents) remains rooted in their original culture. Their sons and daughters (second generation) enter the school system of the new country, and they are assimilated into the culture of this country. Simultaneously, however, these children are socialised in their homes, which creates a kind of cultural schizophrenia in them. [Third generation] will be fully integrated into the new country, in all senses, linguistically, culturally, socially and professionally (Quintana 1992, 75).

Some definitions of multicultural education were advanced. The following definition is very illustrative, catching the subtle message underlying all the congress discourses:

Multicultural education is founded on humanistic educational trends, and is concerned with human rights, social justice and diversity. It can be considered a qualitative-type education designed to help students choose among various models, alternatives and opportunities existing the with the vast range of our culture. [...] [We must recognise] the value of different cultural groups as a condition for the national unity (Pérez 1992, 60-61).

\subsection{Salamanca Congress}

Some months ago, Spanish educators celebrated their tenth National Congress of Pedagogy, entitled 'Intercultural Education in the Perspective of a United Europe.' All contributions presented at this congress dealt with multicultural education or intercultural education, and reflected a multitude of educational science approaches. There were thirty major papers, covering educational policy, educational planning and school organisation, curriculum, teacher education, research, and linguistic issues.

Evidently, there is not enough space to address each one of these contributions. In general, however, all contributions shared certain characteristics: 
- 'Intercultural education' is again the favoured term, because 'it expresses more direct intentions, attitudes and behaviours consistent with the principle of a better mutual understanding among students from diverse cultures' (Etxeberria 1992, 45), and because 'interculturalism is more objective than multiculturalism, which has always tended to refer to assimilation' (Colom 1992, 75).

- There is limited knowledge (we refer to statistical data or qualitative studies) of cultural or ethnic diversity in schools, a limitation that leads to constant speculation. None of participants talked about his/her previous research background on the topic . . . because none of them had it!

- Papers lacked an anthropological foundation. Usually Spanish educators are unaware of how the concept of culture has been developed in anthropology. They are also unaware of trends in anthropology in general. An extreme position can be found in García-Carrasco's work (1992), who thinks that anthropologists have never showed any interest in the cultural transmission process (p. 20), and does not know the difference between emic and etic perspectives (see p. 17).

- The omnipresence of Europe as the only referent of multi(inter)-cultural education. Spanish educators tend to believe that multicultural education is justified because of the new sociopolitical framework in Europe, the future European labour market and future European identity and citizenship.

\subsection{Sitges Congress}

There was a special focus on the so-called 'level of tolerance' problem at this congress. Participants discussed to what extent our schools, and our society are prepared to receive a foreign population. Arenas $(1992,61)$, for instance, wrote:

No community is affected by the arrival of a new population equal to or less than $10 \%$ of its original population. Problems begin to appear at $20 \%$... We ask: what does 'new population' mean? Or, what does 'coming from outside' mean? A French daily, Liberation (Sep.-1-1983) posed this question: 'who is not an immigrant?.' It reported that a third of all French people in 1983 (about 18 millions) were either first, second or third generation immigrants (in Gökalp 1987).

Lack of knowledge and conceptual poverty present themselves here again. One author described immigrants as belonging to different races (Siguan 1992, 10) because, he argued, they have a different skin colour. Arenas $(1992,63)$ believes that 'they come from another world [ . . . ] they belong to very distant civilisations.' Are these misconceptions simply a consequence of inadequate history lessons? Or, are we witnessing the 'racialization' of culture, that is, the new racism? No matter how migrants were categorised, some authors seem to have no doubts with respect to their educational prospects in the new society: 
No matter how wide or narrow the gap is, no matter how homogeneous or diverse the immigrant population is, the real problem remains the same: to reach the social and cultural integration of these children in the society that receives them (Siguan 1992, 10).

Superficially, these discourses seem to defend interculturalism: the respect for diverse cultural identities, the equalisation of opportunities, etc. The deep message, however, argues for pure assimilation.

\section{Current research}

The investigation of topics relating to multicultural education has just begun in our country. In fact, the first steps can be found in a resolution adopted by the DGIEE (January 1991), in which a series of scholarships were offered to investigate immigrant populations. In this section, we will briefly describe some of the main research projects currently being undertaken. All of them are funded by CIDE, an MEC subdepartment. MEC called for project proposals under a suggestive and detailed title: 'Educational situation of immigrants: educational background and labour training; children's schooling; Spanish language learning and cultural integration; intercultural education experiences in Spain and other European countries.'

In one of the projects currently being funded, Ortega and associates (1991) are designing a program for the social and educational integration of ethnic and/or cultural minorities in Castilla-León (Northern Spain). This study uses interviews and questionnaires as basic tools for data gathering. Questionnaires are also the main method being used in the project headed by Calvo (1992). This investigation is part of a wider study focusing on prejudices and attitudes toward diversity in schools. In his project, Merino (1992) seeks to identify and to define the principles that must guide classroom practice with immigrant children in elementary school by adapting the curriculum planning. This is one of the studies taking place in the Madrid area.

Bergere Dezaghi (1992) is trying to detect the educational level of immigrant children living in Madrid. Also he is attempting to conduct a census of immigrant children who attend preschool and elementary levels, and to analyse the degree of school integration by using measures related to academic success, mastery of Castilian language, effective integration in the classroom, etc. Bartolome and her associates (1992) are evaluating immigrant children's classroom situations. They are combining quantitative and ethnographic techniques in order to understand educational relationships in schools with mixed pupil populations. Martin (1992) intends to design and to set up instructional material that deals with cultural diversity and the problems of passive coexistence in contemporary societies. It is a project clearly directed to improving certain aspects of social science teaching-learning processes in classrooms.

The Ioé Group's study (1992) focuses on the Moroccan population. They want to assess the educational level of Moroccan children in Madrid and Barcelona, to analyse the pedagogical practices related to intercultural matters, and to research the 
mutual social representations held by different social agents in this process. This project addresses the educational problems faced by immigrant Moroccan children at compulsory education levels. Interest in this population stems from the growing significance of the Moroccan community in Spain. The most recent official data show that the Moroccan population represents $75 \%$ of African residents in our country and $14 \%$ of the total foreign population legally settled in Spain. The insertion of Moroccan children into the Spanish school creates a cultural ambivalence in their lives, given the large differences that exist between the Spanish educational system (public or private) and the cultural traditions associated with a Muslim country like Morocco.

The project initiated by Mesa and her associates (1992) concentrates on Muslim children attending schools in Melilla (a Spanish city in North Africa). These children are living in what can be defined as a disglossical linguistic environment. The official language in this city and in the schools is Spanish, but these children speak an Arab dialect known as 'chelja' within the family context. When these children enter the preschool level, many of them do not know how to speak Spanish. This project intends to investigate bilingualism among Muslim pupils. The Illinois Test on Psycholinguistic Abilities (ITPA) is being used as a measurement instrument because it offers a means by which to evaluate those psycholinguistic functions involved in the communication process. Furthermore, it can provide information pertaining to the improvement of children's linguistic performance. Subtests scores assist in the development of training and compensation programs for children with low scores.

Finally, we need to mention our own project (García Castaño 1992), which covers six provinces (along the Spanish Mediterranean coast). Our project seeks to describe the ethnic and/or cultural diversity that exist in schools, to understand how schools cope with diversity and what cultural models are shared in Spanish society with respect to the presence of 'others' in schools. The ethnographic method constitutes the basis of our investigation, but there is a certain heterogeneity of approaches, because group members come from different academic backgrounds (educators, sociologists, social psychologists, and anthropologists), and different interests or perspectives (Moroccan researchers provide the project with extremely rich insights that Spanish researchers lack).

\section{Developing legislation between assisting immigrant populations and compensatory education}

\subsection{Labour}

The virtual absence of specific laws dealing with immigrant populations shows how recent concerns in Spain are regarding these topics. Until 1991, the government institution dedicated to migration affairs was called Dirección General del Instituto Español de Emigración (as we stated earlier, emigration has still outpaced immigration during the last few years). The Dirección General de Migraciones (DGM) was created by Royal Decree (1458/1991, October 11th), to replace the former institution. In its preamble, the Royal Decree explains the reason for this change: 
The economic and social evolution experienced by our country during the recent years has affected the direction and volume of migratory flux. In the structure of the Department of Labour and Social Security, displayed in the Royal Decree 530/1985, April 8th, the Dirección General del Instituto Español de Emigración (General Direction of the Spanish Institute for Migration) received responsibilities in matters of immigration, though it kept its traditional focus on emigration. The current reforms attempt to change the General Direction, not only by modifying its name, but also its structure. This provides a balance with respect to migration patterns, whose number and situation require specialised attention, and by establishing new functions: support for return migrants, assistance in the area of immigration, and particularly the implementation of an active migration policy. (B.O.E. 1991, 33131).

This 'new' institution is divided into three main sections (called General Subdirections), one of which is concerned exclusively with immigration. Its tasks include:

a) To assess the need of foreign workers

b) Recruitment and channelling of migratory fluctuations

c) Organisation and management of foreign labour

d) To follow-up and evaluate the labour aspects associated with immigration fluctuations.

As these tasks reveal, there is a focus on the labour market, and there is no mention of educational issues. However, one of the other two subdirections, 'Social Promotion and Integration,' is intended to 'design and manage programs dealing with the social promotion and integration of immigrants.' Several months before the creation of DGM, legislation called for the development of four programs to benefit immigrants.

- Program 1. Contributions to improving the knowledge of one's mother tongue and culture. The goal is to foster the integration of immigrants into Spanish society. Simultaneously, however, there is a call to respect a person's cultural identity through courses in the Spanish Language and in one's mother tongue.

- Program 2. Contributions to training activities in order to reach necessary labour qualifications.

- Programs 3 and 4. Contributions to activities aimed at the social integration of immigrant workers, promoting the creation of associations, etc.

Parallel to the development of research on immigrants, there has been increasing legislation regarding social assistance for Spanish migrants. Immigrants (that is the non-Spanish population) have only recently begun to benefit from these laws. In addition, diverse agreements between the Spanish government and other countries have been made in order to improve the situation of both emigrant and immigrant populations. 
The Ley de Extranjería (Law on Aliens) contains specific legislation on immigrants. It was passed in 1985. The goal is to establish the conditions necessary to legalise the presence of foreigners in Spain. Even after the past seven years, many immigrants have not yet 'legalised' their situation. Many of those who have done so are in the process of reuniting their families. This last point is particularly important for Spain, because the completion of this reunification process will significantly increase the number of immigrant children in our country. At present, most Third World immigrants come to Spain looking for a job, but leave their families in country of origin.

\subsection{Education}

A brief review of the scarce legislation on multiculturalism existing in Spain will make us see even more clearly that this field is a newcomer to the political and academic stages. Spanish participation in the European Community's 'Ad hoc' group on educational treatment of immigrant children proves that our country has become interested in these matters. However, it is our impression that Spanish political authorities do not consider multiculturalism to be an especially significant issue, at least not important enough to warrant extensive legislation.

The law that regulates education rights (LODE) explicitly refers to the right of resident foreigners to be included in the Spanish educational system. This norm does not distinguish among different types of immigrants, and applies to all legal situations. Nevertheless, the recognition of this right is not enough. It is necessary, for example, to grant a free education to economically disadvantaged immigrant children, and to reach a quality standard in this education. There is no specific chapter in LOGSE dedicated to the intercultural or multicultural education of immigrants. If this general law were to be written today, it would undoubtedly contain many references to this issue.

However, LOGSE notes that full education implies 'the development of abilities to live in freedom, tolerance and solidarity in a critical way and within a society with multiple value systems.' Later, it asserts that 'education provides a vehicle to fight against discrimination and inequality, whatever the causes are: race, sex, creed or ideology ...' Among the ultimate goals of the Educational System, LOGSE includes two that relate to our field:

- 'To promote respect for essential rights and freedoms, as well as to exercise tolerance and freedom within the democratic principles of coexistence';

- 'Education to promote peace, co-operation and solidarity among peoples .'

Among its basic principles pertaining to educational activity, LOGSE includes:

- 'Actual equal rights between sexes, the rejection of all types of discrimination and respect for all cultures.' 
LOGSE contains the principles that must guide educational activities dealing with immigrants: a) an underlying curriculum theory; b) the autonomy of each school; c) community involvement in approving of the educational projects developed by schools; d) the adjustment of goals, contents, methodology and evaluation to the characteristics of each school; e) compensatory activities aimed to eliminate inequalities.

There is little to say about specific legislation regarding the education of immigrant children. Obviously, there are some laws dealing with the validation of academic titles (especially in higher education) for foreign students, but these are not the kind of immigrants we are interested in here. Subtle attention to immigrant education can be found in the Royal Decree 1618/1990, December 14th, which regulates the National Plan of Training and Professional Insertion. Within this plan, there is a specific subplan dedicated to 'marginal' groups like the handicapped, emigrants and immigrants, and other groups not included in the rest of the general plan:

The Spanish Institute for Employment, through those collaborations developed in agreement with the General Direction of the Spanish Institute of Emigration, and with non-government institutions and organisms with experience in this field, will develop in the national territory a series of activities in the area of counselling and professional training to assist foreigners who, legally residing in Spain, have the right to be employed in this country, in agreement with the current laws. (B.O.E. 1990, 37852).

Apart from these details, there is no legislation dealing with the educational affairs of immigrants, though this lack is not absolute. Thus there are some laws that are meant to assist disadvantaged groups, and some immigrant groups have been included in these laws. For example, the education of ethnic and/or cultural minorities is included within the legislation on compensatory education. In the next section we shall discuss the consideration of cultural differences as a target for compensation. This implies a conception of cultural and ethnic differences as a source of inequalities, which leads to academic problems.

\section{Programs presently being implemented}

Leaving aside private or non-institutional actions, there are two programs that address the educational situation of immigrant populations. Both programs have been promoted by government departments (MEC and DEGC) within the general framework of compensatory education. The first program is directed towards Portuguese children. This Spanish-Portuguese program is justified by the presence of Portuguese workers (miners) who live in León (northern Spain). Its origin can be traced to a request made by Portuguese associations, both to the Spanish $\mathrm{MEC}$ and the Portuguese embassy. The following guidelines represent the main ones contained in this program: 
- Schooling of Portuguese children in those centres that are closest to their homes

- Inclusion of Portuguese language in the learning process

- All Portuguese and Spanish students who want to participate in the program can do so

- Additional support to schools with Portuguese teachers

- Additional support to schools by providing instructional materials and extra financial resources

- Elaboration of a specific planning for teacher education, which is organised through the Teachers' Centres and Resources Centres Network, with periodical meetings.

Supplementary activities are:

- Spanish teachers pay work visits to Portugal, particularly to get to know the areas immigrants originate from, as well as gaining an understanding of different aspects associated with their culture, educational system, etc.

- Interchange between Spanish and Portuguese students

- Art exhibitions, theatre, folklore demonstrations, etc.

To us, the participation of Portuguese institutions is the most significant feature of this program. Involvement of the country of origin enriches to a great extent any program in multicultural education involving immigrant children. Their collaboration can be found in all the activities just mentioned.

The second program designed to help immigrant students has been developed by the Catalonian government. From our point of view, the most significant aspect of this program is that it shows that it is necessary for regional governments to pay attention to these problems. When the presence of foreign children in schools starts to become numerically important, specific educational treatment becomes an urgent necessity.

The goals of this program are:

- To sensitise teachers to the new multicultural situation in Spanish society and the need to establish a debate among cultures to overcome racism and xenophobia.

- To elaborate criteria to be used by schools when developing instructional guidelines that take into account the cultural diversity present in society, including new topics on peace education, human rights, etc. Also, facilitating knowledge, attitudes and values that lead students to live in a multicultural society. 
- To develop materials, documents, and bibliographical resources on cultures existing in Catalonia, as well as providing support to schools involved in analysing instructional materials currently being used.

- To participate in teacher education programs.

- Analysis of linguistic problems faced by children with different mother tongues, and assisting them in learning the new language. Co-operation in improving the relationships between schools and families, and in solving problems like absenteeism, dropout, etc. Most students who benefit from this program, who attend the schools closest to their homes, have an Arab background. There are 55 teachers and five social workers in this program. These individuals strive for linguistic integration, and teaching the Arab language in conjunction with Arab groups. The intervention models can be summarised as follows:

Help to students:

- To reach comprehensive schooling.

- To assess learning levels.

- To establish 'correct' goals, in collaboration with the teacher; to obtain the necessary abilities to permit a good intellectual and social development.

- Depending on students' characteristics and school resources, the compensatory education teacher will provide an individualised attention to each student.

- To provide the student with the minimum resources (books, accommodation, etc.) needed to guarantee regular school attendance, in those areas where the school lacks such resources.

- To help students preserve their culture, their roots and language through Arabic assistant teachers.

Advice to teachers:

- Direct collaboration with teachers in designing, timing and setting up a general plan of action dealing with these children.

- To make available directly any appropriate materials that deal with the students' cultural backgrounds.

- To establish contacts, if necessary, between social services and families.

Zone action:

- Counselling teachers (who do or do not have immigrant students in their classrooms) in order to jointly tackle the problems experienced by these children. 
- Including 'Interculturalism in school' in teacher education programs and inservice workshops.

- Co-ordination of educational services by the inspection agency.

Social workers included in the program help families by:

- Gradually promoting participatory attitudes within family and community contexts.

- Solving problems related to school absenteeism, health, nutrition, etc.

- Counselling families in order to improve the family-school relationships.

Examples of other institutional efforts can be found in some materials designed by the Centre for Pedagogical Resources La Pau (Centre de Recursos Pedagògics LA PAU) in Barcelona, or those designed by the teacher's group Rosa Sensat, also in Barcelona. In addition some materials have been developed by ICE's from different universities. These ICE's have organised workshops and short courses in which practices and problems related to the schooling of immigrant children schooling are analysed.

In some, we are still in the initial stages of embracing multiculturalism. However, the interest in interculturalism and the investigation and implementation of new programs will certainly grow in the future years. In this respect, the current inclusion of multicultural education in university programs is quite meaningful.

Address for Correspondence: Laboratory of Anthropology, University of Granada 18071 Granada, Spain

\section{References}

Alegret, J.L. (1992) Racismo y educación (49-51). In: Fermoso, P. (ed.) Educación Intercultural: la Europa sin fronteras. Madrid: Narcea.

Arenas, J. (1992) Los inmigrantes y la escuela desde la perspectiva catalana. Siguan, M. (ed) La escuela y la migración en la Europa de los 90. Barcelona: ICE- HORSORI.

Bartolome, M. (1992) Diagnóstico de las diferencias étnicas y de los procesos educativos desarrollados en la Educación Primaria. Barcelona: CIDE-Universidad de Barcelona.

Bergere Dezaphi, J. (1992) Análisis de los problemas de integración escolar de los niños y niñas de los cinco grupos principales de la Comunidad de de Madrid. Madrid: CIDE- Universidad Complutense de Madrid.

Calvo, T. (1992) Igualdad de oportunidades, respetando las diferencias. Integración de las minorías, iolerancia en la mayoría y educación intercultural para todos. Madrid: CIDE- Universidad Complutense de Madrid.

Colectivo Ioé (1992) Escolarización de niños y niñas marroquíes en España. CIDE.

ectivo Ioé (1992a) España frontera sur de Europa. La inmigración extranjera en España: sus características diferenciales en el contexto europeo. Papers presented to the III Jornadas Estatales sobre Perspectivas del Trabajo Social: Inmigración-Emigración. Granada.

Colom, A. (1992) Identidad cultural y proyectos supranacionales de organización social. Educación Intercultural en la Perspectiva de la Europa Unida X Congreso Nacional de Pedagogía (p. 67-85).

Salamanca: Sociedad Española de Pedagogía-Diputación Provincial. 


\section{F. Javier Garcia-Castaño and Rafael A. Pulido Moyano}

Etxeberria, F. (1992) Interpretaciones del interculturalismo en Europa. Educación Intercultural en la Perspectiva de la Europa Unida. X Congreso Nacional de Pedagogía (p. 39- 65). Salamanca: Sociedad Española de Pedagogía- Diputación Provincial.

Garcia Castaño, F. (1992) La escolarización de niñas y niños inmigrantes en el Sistema Educativo Español. Estudio comparado entre diferentes provincias españolas de la sifuación en las escuelas de los hijos de inmigrantes extranjeros desde la perspectiva de la antropología social. Granada: CIDE-Universidad de Granada.

Garcia Castaño, F.; Pulido Moyano, R. (1992a) Educación Multicultural y Antropología de la Educación. In: Fermosos, P. (ed) Educación Intercultural: la Europa sin fronteras. (p. 35- 69). Barcelona: Narcea.

Garcia Castaño, F.; Pulido Moyano, R. (1992b) From the Recognition of Intracultural Diversity to the Design of Multicultural Education for Everybody. Paper presented to the International Symposium of Europe in Education. Bad Urach (FRG): CIDRE.

Garcia-Carrasco, J. (1992) Bases sociales y antropológicas de la educación intercultural. Educación Intercultural en la Perspectiva de la Europa Unida. X Congreso Nacional de Pedagogía (p. 15-37). Salamanca: Sociedad Española de Pedagogía-Diputación Provincial.

Gökalp, A. (1987) Los hijos de inmigrantes en Europa Occidental: socialización diferencial y problemática multicultural. Revista Internacional de Ciencias Sociales, Vol. 36, n. 3, 515-529. 


\section{Contents}

Editorial

Cultural and Linguistic Diversity in the Education Systems of the European Community

Fritz Wittek, Marianne Nijdam, Piet Kroeger

Intercultural Education in French-speaking Belgium: an overview

of ideology, legislation and practice

Marco Martiniello and Altay Manço

Intercultural Education: a Danish point of view

Else Lammers

Bilingual Policies in Luxemburg

Serge Kollwelter

Intercultural Education: The Dutch Way

Willem Fase

Portugal: a Profile of Intercultural Education

Maria Beatriz Rocha Trindade, Maria Luisa Sobral Medes

Multicultural Education: Some Reflections on the Spanish case

F. Javier Garcia-Castaño and Rafael A. Pulido Moyano

IAIE News

Reviews 